\title{
Incidental finding of accessory lobe of liver during sleeve gastrectomy: A case report and review of literature
}

\author{
Vasanth Stalin ${ }^{1 *}$ and Ravi Teja Pasam ${ }^{2}$ \\ ${ }^{1}$ Ascension St. Mary's Hospital, Saginaw, Michigan, USA \\ ${ }^{2}$ Lahey Clinic, Burlington, Massachusetts, USA
}

\begin{abstract}
We present an incidental finding of Accessory Lobe of Liver (ALL), attached to the left hepatic lobe by a mesentery, noted during laparoscopic Sleeve gastrectomy. The patient was asymptomatic and there were no Liver Function Test abnormalities prior to the surgery. Most of the ALLs are asymptomatic and diagnosed incidentally during surgery, autopsy or cross-sectional imaging. Patients can sometimes present with recurrent unexplained abdominal pain or fluctuating Liver Function Tests. Such cases might need surgical intervention based on clinical scenario. Rare and serious complication of ALL is torsion, which necessitates surgical resection.
\end{abstract}

\section{Introduction}

Various anatomical variants of the liver and gallbladder have been excellently described by Thomas Cullen almost a century ago [1]. Accessory lobes of liver (ALL), which was first described by Morgagni in 18th century [2], was one amongst the numerous variants that he has compiled from his extensive literature review. As per Cullen, accessory lobes can be connected to the rest of the liver by a liver pedicle or mesentery. Although he described that they have little clinical importance as they do not cause any symptoms, he also mentioned a Case report of strangulation of the Accessory lobe. Since then, there have been multiple Case reports and published studies which have stressed the asymptomatic nature of this anatomic variability and the rare presentations of torsion. Here, we present a case of incidental finding of an ALL during laparoscopic Sleeve gastrectomy and an extensive review of literature regarding etiology, incidence, and presentation of ALL [3-10].

\section{Case}

Our patient was a Morbidly obese 44-year-old asymptomatic female with normal Liver Function Tests prior to surgery. Standard laparoscopic access to the peritoneal cavity was established. When we attempted to place the liver retractor, we noted extra-anatomical liver tissue attached to the left lobe of liver by mesenteric tissue. It was important to retract this ALL for unhindered visualization of the gastroesophageal junction, before a Sleeve gastrectomy could be performed. Although we had some trouble initially retracting the ALL with our liver retractor, we were able to do so eventually with some maneuvering (Figure 1). The ALL had a smooth contour and did not seem to be different from the rest of the liver macroscopically. The ALL measured about $8.1 \times 6.8 \times 3.3 \mathrm{~cm}$.

\section{Discussion}

ALL is a rare congenital anatomic variant of liver. The exact incidence is unknown, and it Is often diagnosed incidentally on imaging [11] or during abdominal surgery/autopsy [4]. Based on multiple studies that evaluated the presence of ALLs on imaging and

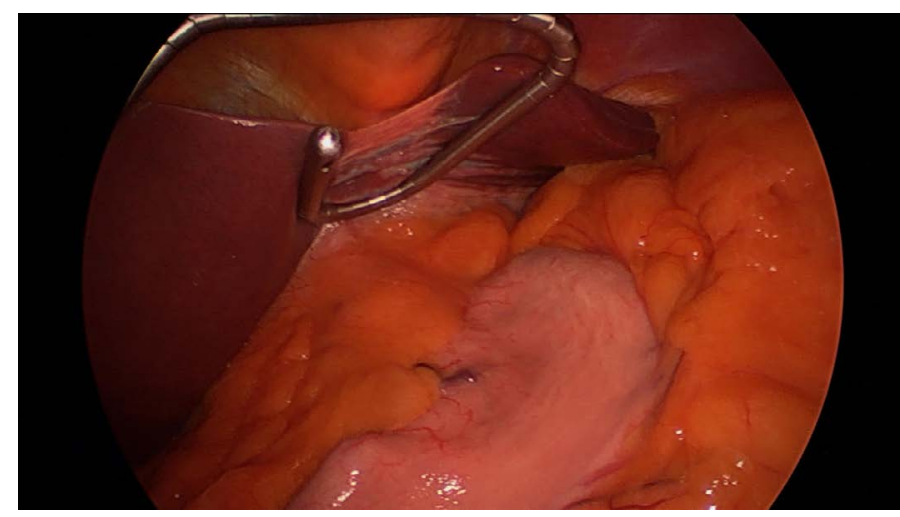

Figure 1. Accessory lobe of liver (ALL) attached to the left hepatic lobe by mesentery. The Liver retractor is retracting the liver and ALL away from the field of surgery

laparoscopy, it is safe to say that the incidence is $1 \%$ or less [12-14]. A recent study published by Ozaki, et al. looking at the Computerized Tomography images of the abdomen seems to indicate that the incidence of small ALLs could be around $1 \%(\mathrm{~N}=3269)$ [14]. While the study by Sato, et al. which evaluated incidence during laparoscopy, reported $0.7 \%$ incidence $(\mathrm{N}=1802)$ of ectopic liver and ALLs, a similar study by Orlando et al. reported zero cases in 2650 patients. Sato, et al. and Ozaki, et al. reported that the majority of the patients with these anomalies were males.

The etiology of the of the ALLs is unclear but it is often thought to be due to anomalous embryonic development. In the Pediatric population, it was noted to be present concurrently with various abdominal wall defects [3]. Possible etiologies proposed by authors in the past include

${ }^{\star}$ Correspondence to: Vasanth Stalin, Ascension St. Mary's Hospital, Saginaw, Michigan, USA, E-mail: dr_vasanth@yahoo.com

Received: December 14, 2020; Accepted: December 24, 2020; Published: December 28, 2020 
development of liver tissue along an anomalous embryonic vein [4], tissue formed by displacement of primitive rudiment of the liver [5], persistence of mesodermal septa during liver proliferation [6], or further branching of foregut diverticula [7]. The accessory lobes can arise from the right lobe, left lobe or even from the gallbladder. Intrathoracic ALLs have also been reported [8-10].

ALLs are classified as small if the lobe weighs $30 \mathrm{gm}$ or less and large if it is greater than $30 \mathrm{~g}$ [15]. The clinical significance of this classification is unknown. As mentioned above it can be attached to the liver by normal liver tissue or a mesentery. Histologically, the tissue in the ALLs seem to have normal hepatic architecture $[5,16,17]$.

Patients with ALLs are usually asymptomatic. Recurrent abdominal pain attributed to the ALLs has been reported in the past [5]. It can also present as unexplained abnormal Liver Function Tests [18]. Khan, et al. [19] compiled case reports of torsion of the ALL, which seems to be rare, but is the most serious complication of this anatomical variant [19]. Ladurner, et al. [20] reported a case where the patient required Orthotopic liver transplantation due to severe ischemia caused by torsion of the ALL [20]. Rare presentations such as blunt abdominal trauma leading to isolated rupture of the ALL [21], focal nodular hyperplasia of the ALL [22], extrahepatic portal vein obstruction [23] have also been reported in the literature.

Ectopic liver tissue and Riedel's lobe are some of the other variants of liver anatomy which are at times reported as accessory lobes. It is important to note that liver tissue that is not connected to the liver in any form is considered to be an Ectopic liver and not ALL [15]. On the other hand, Riedel's lobe is a misnomer. It is just a downward projection/extension of the right lobe of the liver. Of note, there have been reports of pedunculated hepatocellular carcinoma (HCC) as well $[24,25]$. So, HCC should be part of the differential in the appropriate clinical context, especially in those patients with cirrhosis.

\section{Conclusion}

In conclusion, ALLs are normal anatomical variants with likely low incidence, detected incidentally on imaging or during surgical procedures/autopsy, with torsion of the ALL being the most serious complication. In patients with unexplained recurrent abdominal pain corresponding to the area of the ALL or elevated LFTs in the presence of an ALL, the possibility of ALL causing these symptoms and lab abnormalities should be considered. If there is strong suspicion that the ALL is the possible etiology of symptoms and/or laboratory abnormalities, surgery should be considered on a case-by-case basis. In patients presenting with an acute abdomen and no other obvious abnormality, the presence of an ALL should raise the suspicion of torsion. The presence of ALLs can cause difficulty in accessing the Surgical field, during Foregut surgery. Although there is no literature on this, we believe that every attempt should be made to perform the planned surgery safely, without resection of an asymptomatic ALL.

\section{References}

1. Cullen TS (1925) Accessory lobes of the liver: an accessory hepatic lobe springing from the surface of the gallbladder. Arch Surg 11: 718-764.
2. Morgagni G (2020) De sedibus et causis Morborum, per Anatomen indagatis: libri quinque. Haak. 1761.

3. Corbitt N, Rellinger EJ, Hernanz-Schulman M, Chung DH (2017) Accessory hepatic lobes in the pediatric population: A report of three cases of torsion and literature review. J Pediatr Surg Case Rep 16: 15-18.

4. Chouke KS (1932) A note on an anomalous lobe of the liver. Anat Rec 53: 177-180.

5. Pujari BD, Deodhare SG (1976) Symptomatic accessory lobe of liver with a review of the literature. Postgrad Med J 52: 234-236. [Crossref]

6. Fraser CG (1952) Accessory Lobes of the Liver. Ann Surg 135: 127-129.

7. Ashby EC (1969) Accessory liver lobe attached to the gallbladder. Br J Surg 56: 311 312.

8. Caron J, Bascands J, Cosson R (1970) [Thoracic hepatic lobe]. J Chir (Paris) 100: 213-226. [Crossref]

9. Hansbrough ET, Lipin RJ (1957) Intrathoracic accessory lobe of the liver. Ann Surg 145: 564-567. [Crossref]

10. Kaufman SA, Madoff IM (1960) Intrathoracic accessory lobe of the liver. Ann Intern Med 53: 403-407.

11. Wang C, Cheng L, Zhang Z, Xie T, Ding H, et al. (2012) Accessory lobes of the liver: A report of 3 cases and review of the literature. Intractable Rare Dis Res 1: 86-91. [Crossref]

12. Sato S, Watanabe M, Nagasawa S, Niigaki M, Sakai S, et al. (1998) Laparoscopic observations of congenital anomalies of the liver. Gastrointest Endosc 47: 136-140. [Crossref]

13. Orlando R, Lirussi F (2000) Congenital anomalies of the liver: laparoscopic observations. Gastrointestinal Endoscopy 51: 115-116.

14. Ozaki K, Yoshikawa J, Yamamoto T (2018) Morphometric analyses of small accessory liver lobes using radiological imaging. Clin Imaging 51: 43-49. [Crossref]

15. Collan Y, Hakkiluoto A, Hästbacka J (1978) Ectopic liver. Ann Chir Gynaecol 67: 27 29. [Crossref]

16. Elmasalme F, Aljudaibi A, Matbouly S, Hejazi N, Zuberi MS (1995) Torsion of an accessory lobe of the liver in an infant. J Pediatr Surg 30: 1348-1350. [Crossref]

17. Natarajan S, Jayasudha, Periasamy M, Rangasamy S (2017) Torsion of Accessory Hepatic Lobe. J Indian Assoc Pediatr Surg 22: 55-56. [Crossref]

18. Fogh J, Tromholt N, Jørgensen F (1989) Persistent impairment of liver function caused by a pendulated accessory liver lobe. Eur J Nucl Med 15: 326-327.

19. Khan AM, Hundal R, Manzoor K, Dhuper S, Korsten MA (2006) Accessory liver lobes: A diagnostic and therapeutic challenge of their torsions. Scand J Gastroenterol 41: 125-130. [Crossref]

20. Ladurner R, Brandacher G, Mark W, Iannetti C, Lottersberger C, et al (2005) Complete hepatic ischemia due to torsion of a large accessory liver lobe: first case to require transplantation. Transpl Int 18: 467-469. [Crossref]

21. Garba ES, Ameh EA (2002) Isolated rupture of an accessory liver from blunt abdominal trauma in childhood. Pediatr Surg Int 18: 62-63. [Crossref]

22. Su N, Chen C, Dai Q, Wang L, Yang M, et al. (2020) Focal nodular hyperplasia on an accessory liver lobe: A case report and literature review. Medicine (Baltimore) 99: e21357. [Crossref]

23. Chandramohan A, Pachuau EL, Eapen A (2014) Accessory hepatic lobe: a rare cause of extra-hepatic portal vein obstruction. Trop Gastroenterol 35: 190-193. [Crossref]

24. Horie Y, Katoh S, Yoshida H, Imaoka T, Suou T, et al. (1983) Pedunculated hepatocellular carcinoma. Report of three cases and review of literature. Cancer 51: 746-751. [Crossref]

25. Yeh C-N, Lee W-C, Jeng L-B, Chen M-F (2002) Pedunculated Hepatocellular Carcinoma: Clinicopathologic Study of 18 Surgically Resected Cases. World J Surg 26: 1133-1138. [Crossref]

Copyright: (C2020 Stalin V. This is an open-access article distributed under the terms of the Creative Commons Attribution License, which permits unrestricted use, distribution, and reproduction in any medium, provided the original author and source are credited. 